\title{
DENSIDAD LARVAL DE CHIRONOMIDAE (INSECTA: DIPTERA) EN UN MEANDRO DEL RÍO BOGOTÁ (CAJICÁ, COLOMBIA) DURANTE LA NIÑA 2011
}

Fecha de recepción: 19 de noviembre de 2014 • Fecha de aceptación: 18 de diciembre de 2014

\section{DENSITY OF LARVAL CHIRONOMIDAE (INSECTA: DIPTERA) IN A MEANDER OF THE BOGOTA RIVER (CAJICA, COLOMBIA) DURING LA NIÑA 2011}

Raúl Hernando López Peralta' • Grace Margarita Talero Martín²

\section{RESUMEN}

Entre febrero y septiembre de 2011 (condiciones climáticas La Niña) se evaluó la densidad larval de Chironomidae en tres sectores de un meandro del río Bogotá. Se consideraron algunas variables abióticas para estimar el estado trófico del agua y su influencia sobre estos organismos. La trasparencia (13,0-44,0 cm), temperatura $\left(15,2-18,8^{\circ} \mathrm{C}\right), \mathrm{O}_{2}(0,5-7,8 \mathrm{mg} / \mathrm{l})$, dureza $(1,3-3,0 \mathrm{mg} / \mathrm{l}), \mathrm{pH}(5,2-7,0)$, conductividad $(194-718 \mu \mathrm{S} / \mathrm{cm})$, $\mathrm{Fe}^{2+}(0,1-0,9 \mathrm{mg} / \mathrm{l})$, sólidos totales $(137,0-927,5 \mathrm{mg} / \mathrm{l})$ y relación N/P $(1,0-15,9)$ variaron en respuesta a las Iluvias (0-46,3 mm), aunque el ACP no mostró asociaciones altas. El río manifestó contaminación moderada y aguas eutróficas con tendencia a la hipertrofia ( $N / P=1,0-15,9)$. El sector 3 se diferenció de los otros, debido al vertimiento de aguas allí (K-W p<0,05). Las diferencias cronológicas de la densidad (1-656 larvas/m²) también se atribuyeron a la influencia de las precipitaciones, que definen los pulsos del río, con contrastes más marcados durante La Niña, ocasionando inundaciones, lo que impidió el muestreo entre abril y junio. Dada la gran riqueza genérica de Chironomidae, se requiere acudir a la taxonomía integrativa (caracteres externos y análisis moleculares). Este enfoque ayuda a una mayor y correcta comprensión de la influencia de los patrones ambientales sobre estos organismos. Entre tanto, el valor indicador de esta taxocenosis se considera incierto para el río Bogotá.

Palabras clave: macroinvertebrados, bentos, hemoglobina, lluvia, relación N/P.

Raúl Hernando López Peralta, Dr. rer. nat.

2 Grace Margarita Talero Martín, Bióloga, Especialista en Gerencia de Recursos Naturales. Laboratorio de Hidrobiología, Programa de Biología Aplicada, Facultad de Ciencias Básicas y Aplicadas. Campus Nueva Granada, Universidad Militar Nueva Granada, km 2 vía Cajicá-Zipaquirá, Colombia. Envío de correspondencia: raul.lopez@unimilitar.edu.co. 


\section{ABSTRACT}

Between February and September 2011 (La Niña-like climatic conditions) the density of larval Chironomidae in three sectors of a meander of the Bogotá River was evaluated. Some abiotic variables were considered to estimate their influence and the trophic status of water on these organisms. Transparency $(13.0-44.0 \mathrm{~cm})$, temperature $\left(15.2-18.8^{\circ} \mathrm{C}\right), \mathrm{pH}(5.2-7.0), \mathrm{O}_{2}(0.5-7.8 \mathrm{mg} / \mathrm{l})$, hardness (1.3-3.0 mg/l), Fe ${ }^{2+}(0.1-0.9 \mathrm{mg} / \mathrm{l})$, total solids (137.0-927.5 mg/l), conductivity (194-718 S/cm), and N/P (1.0-15.9) varied in response to rainfall (0-46.3 mm), although the ACP did not show high associations. The river showed moderate contamination and eutrophic waters prone to hypertrophy $(\mathrm{N} / \mathrm{P}=1,0-15,9)$. The Sector 3 differed from the others $(\mathrm{KW} \mathrm{p}<0.05)$, due to the dumping of water there. The chronological differences in such conditions and density (1-656 larvae/ $\left.\mathrm{m}^{2}\right)$ were also attributed to the influence of rainfall, which define the pulse of the river, with a stronger contrast during La Niña, causing floods, which impeded the sampling between April and June. Given the generic richness of Chironomidae, to attend the integrative taxonomy (external characters and molecular analysis) is required. This approach is useful for a better and correct understanding of the influence of environmental patterns on these organisms. Meanwhile, the indicator value of this taxocenosis is considered uncertain for the Bogota River.

Key words: macroinvertebrates, benthos, hemoglobin, rain, N/P ratio.

\section{INTRODUCCIÓN}

El orden Diptera está constituido por insectos holometábolos, dentro de los cuales la familia Chironomidae tiene ca. 15000 especies, de las que 1500 a 2000 (descritas sólo unas 400) habitan en el neotrópico. Es la familia de macroinvertebrados de mayor abundancia y distribución en todos los ecosistemas dulceacuícolas, y con frecuencia es el grupo más diverso y profuso en el bentos de los sistemas fluviales (Ferrington 2008, Rosa et al. 2014); también habita en aguas salobres (Cranston 2000, 2004, Helson et al. 2006, Ferrington 2008, Orendt et al. 2011).

Los quironómidos tienen una tasa reproductiva rápida y alcanzan abundancias muy elevadas (Roldán 2003, Segnini 2003). Las larvas son hidropneústicas y algunas tienen hemoglobina en la hemolinfa (además de cantidades importantes de vitamina A) (Ivleva 1969), lo cual les permite maximizar la captación de oxígeno y soportar concentraciones casi anóxicas (Paggi 2001, Hanson et al. 2010). La mayoría son colonizadoras vertiginosas adaptadas a condiciones fluctuantes y pululan en fondos lodosos y arenosos; consumen principalmente detritus, sedimentos y algas (en especial Bacillariophyceae), aunque eventualmente rotíferos, oligoquetos y larvas de otros insectos; a su vez, son presa de una amplia variedad de organismos, e. g., odonatos, coleópteros, así como peces ornamentales y de consumo humano (Cyprinidae y Cichlidae) (Segnini 2003, Navarrete et al. 2004, Galizzi et al. 2012), lo que les atribuye un rol muy relevante en las tramas tróficas (Acosta 2009, Acosta et al. 2009).

Muchos miembros de Chironomidae son considerados indicadores de las condiciones limnológicas (Cranston 2000, 2004, Helson et al. 2006 Lee et al. 
2006, Ha \& Choi 2008). Su identificación a nivel de familia basta en el uso de índices como el BMWP (Biological Monitoring Working Party) originado en 1970 en Inglaterra, del que ha derivado el BMWP/ Colombia (Roldán 2003, Liévano \& Ospina 2007, Roldán \& Ramírez 2008).

Aunque se ha refutado la confiabilidad de este índice (Forero et al. 2014) y la familia Chironomidae en la bioindicación (Puntí et al. 2009, Al-Sham et al. 2010), han sido considerados en la evaluación de varios ríos de Colombia, por otros autores (e. g., Lozano 2005, Bernal et al. 2006, Guevara et al. 2006, Liévano \& Ospina 2007, Liévano 2013, Posada et al. 2008, Montoya et al. 2011, Rodríguez 2011, Duque 2013, CORPONARIÑO et al. 2014).

Para el trayecto del río Bogotá que atraviesa la Sabana de Bogotá se conocen los siguientes trabajos sobre macroinvertebrados bentónicos que incluyen quironómidos: Lozano (1995), Ospina et al. (1999), Ruiz et al. (2000a, 2000b), Riss et al. (2002b), Gutiérrez et al. (2004), Prat et al. (2014) y Ochoa \& Castañeda (2010). En el meandro evaluado sólo se han realizado los estudios de Gómez \& Contreras (2009) y Ramírez et al. (2013), enfocados a la aplicación del índice BMWP/Colombia.

La abundancia de los quironómidos se ha relacionado con el ciclo hidrológico (e. g., Medina \& Paggi 2004, Ribeiro \& Uieda 2005, Chávez \& Orantes 2010, Chalar et al. 2011, Montoya et al. 2011, Forero et al. 2014), el cual se ve afectado por la variabilidad climática global, que se relaciona con el ciclo conocido como El Niño-Oscilación del Sur (ENOS) que incluye la fase cálida El Niño y la fase fría La Niña. Estos eventos se originan con recurrencia en aguas superficiales del océano Pacífico ecuatorial y están asociados con interacciones atmosféricas (lluvias, presión del aire, circulación atmósferica) que ocasionan alteraciones climáticas y generan impactos de diversa índole, con frecuencia extremos, en diferentes regiones del mundo (Andreoli \& Kayano 2005). En amplias regiones de Colombia el ENOS ejerce una influencia climática a largo plazo (Gutiérrez \& Dracup 2001, Poveda et al. 2010), como en el área de estudio (Laverde \& López 2012, Ramírez et al. 2013) y el resto de la Sabana de Bogotá (Pabón \& Torres 2007).

Al igual que en los sistemas fluviales de otras regiones, es de esperar que la densidad y distribución espacio-temporal de las larvas de Chironomidae en el meandro del río Bogotá esté definida por las condiciones físico-químicas, sobre las cuales influye el ciclo hidrológico y, por ende, los pulsos del río, en respuesta al episodio La Niña imperante en 2011.

\section{MATERIALES Y MÉTODOS}

\section{Área de estudio.}

Con una cuenca de 6000 km², el río Bogotá es el más grande y representativo de la Sabana de Bogotá, por su importancia ecológica, social y económica. Aunque la calidad del agua en su nacimiento es buena, su degradación se observa desde la cuenca alta, debido a los vertimientos de ca. 170 curtiembres, con alto contenido de grasas, aceites y metales pesados, que contribuyen a la contaminación orgánica y bacteriológica del río en su trayecto, aumentada por otros aportes industriales y de aguas residuales. En varios sectores las actividades agropecuarias han cambiado a parcelaciones rurales para la recreación y urbanización galopante, sobre todo en la periferia de Bogotá, generando residuos sólidos con impactos negativos en el río y otros cuerpos de agua. Además, es evidente el aumento de sedimentos por la erosión edáfica asociada al avance de la frontera agrícola hacia el páramo y subpáramo, generando el deterioro de la cobertura vegetal (DNP \& MAVDT 2004).

El meandro de estudio hace parte de la cuenca media del río Bogotá y se ubica a 2558 msnm en la zona rural del municipio de Cajicá (Cundinamarca) a 9 km de Bogotá. El clima es frío, semi-seco, con una temperatura promedio de $13^{\circ} \mathrm{C}$ y un patrón de 
precipitaciones bimodal (<1000 mm), con un pico entre abril y mayo, y el más alto entre octubre y noviembre (CAR 2009). Como el resto de Colombia, esta área está afectada periódicamente por las anomalías climáticas El Niño y La Niña (Pabón \& Torres 2007, Laverde \& López 2012, Ramírez et al. 2013, IDEAM et al. 2014). La época de estudio se vio afectada por uno de los episodios La Niña más fuertes registrados a la fecha (IDEAM 2011, IDEMA et al. 2014).

La longitud del meandro es de ca. 1 km, limita al norte y sur con cultivos de flores, al este con un campo de golf y al oeste con el Campus Nueva Granada de la Universidad Militar Nueva Granada (Campus UMNG) (Fig. 1).

\section{Obtención de las muestras y datos abióticos.}

Se consideraron seis fechas en 2011: febrero 08, marzo 29, julio 11, agosto 01 y 29, y septiembre 26. Se establecieron tres sectores de muestro ubicados en la orilla del río, así: 1: 456'33.78" $\mathrm{N}-74^{\circ} 00^{\prime} 27.10^{\prime \prime} \mathrm{O}$, 2: $4^{\circ} 56^{\prime} 25.02^{\prime \prime} \mathrm{N}-74^{\circ} 00^{\prime} 17.50^{\prime \prime} \mathrm{O}$ y $3: 4^{\circ} 57^{\prime} 33.78^{\prime \prime} \mathrm{N}-$ $74^{\circ} 00^{\prime} 28.10^{\prime \prime} \mathrm{O}$ (Fig. 1).

Para la captura de los organismos, se siguió la recomendación de realizar tres replicas por unidad muestral para aplicar los métodos estándar en evaluaciones rápidas de macroinvertebrados bentónicos fluviales (Barbour et al.1999). En cada sector se extrajo sedimento mediante una red Surber de $25 \mathrm{x}$ $25 \mathrm{~cm}\left(0.06 \mathrm{~m}^{2}\right)$ y abertura de malla de $250 \mu \mathrm{m}$, dispuesta contracorriente cerca de la orilla. Con una pala graduada $(\mathrm{cm})$ se removieron los primeros 5-10 $\mathrm{cm}$ del sustrato, se guardó en bolsas de polietileno y se fijó con alcohol al 70\% (Roldán 1996).

Con sondas Schott $^{\circledR}$ se midió la temperatura $\left({ }^{\circ} \mathrm{C}\right), \mathrm{pH}$, conductividad $(\mu \mathrm{s} / \mathrm{cm})$ y oxígeno disuelto $(\mathrm{mg} / \mathrm{l})$ y con un fotómetro Visocolor MachereyNage ${ }^{\circledR}$ se estimaron las concentraciones de dureza total (DT), $\mathrm{NO}_{2}^{-}, \mathrm{NO}_{3}^{-}, \mathrm{NH}_{4}^{+}, \mathrm{PO}_{4}^{3-}$ y $\mathrm{Fe}^{2+}$ (mg/l). La transparencia $(\mathrm{cm})$ se estableció con un disco Secchi. A partir de marzo se obtuvieron muestras de agua de $50 \mathrm{ml}$ para estimar los sólidos suspendidos, disueltos y totales (SS, SD y ST).

Los datos pluviométricos mensuales fueron obtenidos de la estación 2120159 ALCO-Cajicá (0454'N$\left.74^{\circ} 00^{\prime} \mathrm{O}, 2590 \mathrm{msnm}\right)$ del Sistema de Información Climatológica e Hidrológica de la Corporación Autónoma Regional de Cundinamarca (CAR). Ante la ausencia de valores mensuales para enero y febrero se consideraron los de la estación 2120074-Zipaquirá

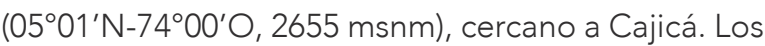
datos para las fechas de muestreo (excepto el 08 de febrero) fueron suministrados por la estación meteorológica del Campus UMNG.
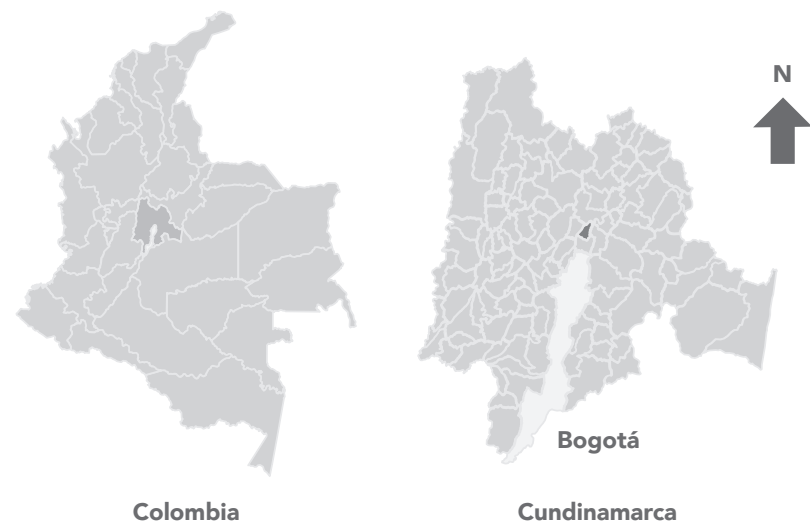

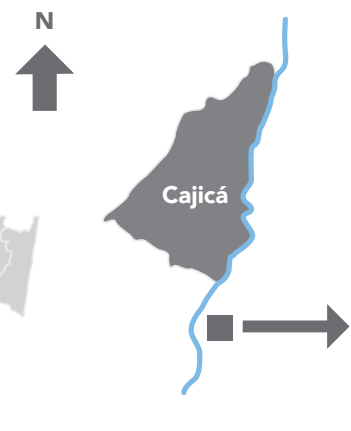

Río Bogotá

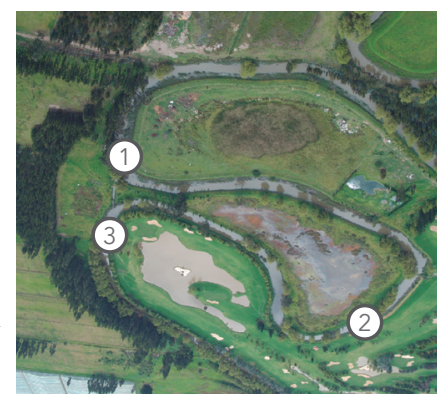

Meandro Campus UMNG

Figura 1. Localización del área y los tres sectores de estudio en el meandro del río Bogotá, Campus UMNG (Cajicá, Cundinamarca). 


\section{Granulometría}

Las muestras de sustrato se llevaron a peso constante en un horno a $105^{\circ} \mathrm{C}$ y se tamizaron con mallas de 250, 53 y 45 um para su tipificación granulométrica (análisis de textura) por medio de la escala Udden-Wentworth (Paramo et al. 2012). El mismo procedimiento se siguió con las muestras para la estimación de los SD, SS y ST (mg/l), filtrándolas luego con papel de filtro de fibra de vidrio $(1.5 \mu \mathrm{m})$ (Roldán \& Ramírez 2008). Los pesajes se hicieron con una balanza analítica Ohaus-Explorer ${ }^{\circledR}$.

\section{Identificación de las larvas}

Un tamiz de $60 \mu \mathrm{m}$ sirvió para separar las larvas de Chironomidae del sedimento. La identificación se basó en su habitus, número de segmentos, cápsula cefálica, parapodios anteriores y posteriores, setas procercales y túbulos anales (Ruiz et al. 2000a, 2000b, Riss et al. 2002b, Prat et al. 2011, 2014), observados con un estereoscopio Carl Zeiss Stemi DV4. La densidad se expresó por $\mathrm{m}^{2}$. Los ejemplares se preservaron en alcohol al 70\% para su menor identificación taxonómica posible posteriormente.

\section{Análisis de la información}

En los casos de la granulometría y densidad se emplearon los valores promedio de las tres réplicas. El grado o estado trófico, entendido como el aumento de la concentración de nutrientes por el vertimiento de residuos sólidos y líquidos derivados de actividades antropogénicas (Roldán 1996, Roldán \& Ramírez 2008), se definió mediante la relación $\mathrm{N}: \mathrm{P}\left(\sum\left(\mathrm{NO}_{2}^{-}, \mathrm{NO}_{3}{ }^{-}, \mathrm{NH}_{4}^{+}\right) / \mathrm{PO}_{4}{ }^{3-}\right)$ y los valores $>63$ oligotrofia, 20-27 mesotrofia, 10 eutrofia y $<4$ hipertrofia (Welch 1992).

La influencia de las variables abióticas sobre la comunidad larval de Chironomidae se valoró con un Análisis de Componentes Principales (ACP) previa transformación de las densidades $\log (x+1)$. Para evaluar las diferencias estadísticas entre los sectores de muestreo se efectuó un análisis de agrupamiento (distancia euclidiana cuadrada), considerando todas las variables analizadas y se aplicó la prueba no paramétrica de Kruskal-Wallis (K-W) ( $p=0,05$; significancia del 95\%). En todos los análisis se usó el paquete estadístico STATGRAPHICS Centurión XVI ${ }^{\circledR}$.

\section{RESULTADOS Y DISCUSIÓN}

\section{Identificación de las larvas de Chironomidae}

Todos los especímenes tuvieron las características morfológicas de Chironomidae (Ruiz et al. 2000a, 2000b, Prat et al. 2011). Aunque las larvas de esta familia pueden ser rojas, moradas, azules, verdes o blancas (Cranston 1988, 2004, Epler et al. 2000, Cuda et al. 2002, Gresens et al. 2012), es de resaltar el color rojo brillante de todas las larvas al momento de captura en el meandro del río Bogotá, lo cual podría ser un indicativo inicial de que pertenecen a la tribu Chironomini (subfamilia Chironominae), pues es una de sus características llamativas (Paggi 2001, Hanson et al. 2010), en especial de Chironomus (Cranston 1988) y se debe al alto contenido de hemoglobina (85\%) (Ivleva 1969).

Tal peculiaridad ayuda a sostener el metabolismo aeróbico, aún en niveles casi anóxicos, además de la circulación obligada del agua en las galerías que habitan las larvas, y les permite alcanzar a veces abundancias elevadas (Roldán 2003). Estas características tienen un papel cardinal para establecer las características ecológicas de Chironomus (Barbour et al. 1996, Choi et al. 2001, Roldán 2003, Forcella et al. 2007); tanto, que los niveles de expresión de la hemoglobina se consideran muy buenos biomarcadores en ecotoxicología acuática (e. g., Lee et al. 2006, Ha \& Choi 2008).

Ruiz et al. (2000a, 2000b) elaboraron las claves de identificación para larvas de 16 géneros de Chironomidae de ecosistemas lóticos de la sabana de Bogotá y formaciones montañosas vecinas, en la que 
incluyeron el color en la diagnosis. Es de notar el color rojo de los géneros dela Tribu Chironomini, salvo Paraclodopelma (amarillo).

Sin embargo, se generan dudas sobre esta presunción taxonómica preliminar, pues el aumento en zonas de descarga de aguas residuales también se ha explicado por la concentración de hemoglobina en las larvas de otros miembros de las tribu Chironomini (e. g., Polypedilum) y la tribu Tanytarsini (e. g., Rheotanytarsus), la subfamilia Orthocladiinae (e. g., Thienemanniella) y la mayoría de la subfamilia Tanyponidae (excepto Pentaneurini) (Cranston 1988, Day et al. 2006, Helson et al. 2006). No se halló información sobre la concentración de hemoglobina en estos taxa.

La combinación de los perfiles de hemoglobina y la morfología de la cápsula cefálica también se ha usado para identificar los géneros Thienemannimyia (subfamilia Tanypodynae, tribu Pentaneurini) Chironomus, Cricotopus, Dicrotendipes y Glyptotendipes (Oh et al. 2014).

Aunque cada vez se emplean más los análisis moleculares para resolver dudas taxonómicas, máxime en Chironomus (Guryev et al. 2001, Papusheva et al. 2004), See comment in PubMed Commons belowel color ha adquirido mayor importancia en nuevos estudios de las larvas pues, por ejemplo, en el grupo Cricotopus sylvestris (Orthocladiinae) las especies se distinguen estadísticamente por el patrón de color, mas no por su código de barras de ADN (Gresens et al. 2012). Las larvas de C. lebetis también se diferencian por su color verdoso, por el escaso contenido de hemoglobina (Epler et al. 2000, Cuda et al. 2002). Otras especies de este género sólo han podido diferenciarse citogenéticamente (Petrova s. 2012), pero en verdad la utilidad de Cricotopus como bioindicador se ha relegado, por la dificultad de identificar con precisión sus larvas (Sinclair \& Gresens 2008).

En cualquier caso, la aplicación de Chironomidae en la bioindicación se ha restringido, por la problemática taxonómica de su gran número de especies, más
Tabla 1. Chironomidae hallados en sistemas lóticos de la sabana de Bogotá y montañas circundantes (Ruiz et al. 2000a, 2002b).

Subfamilia Chironominae, Tribu Chironomini

\begin{tabular}{ccc}
\hline Género & Cuerpo & $\begin{array}{c}\text { Cápsula } \\
\text { cefálica }\end{array}$ \\
\hline Chironomus & Rojizo & \\
\hline Dicrotendipes & Marrón rojizo claro & \\
\hline Paracladopelma & Amarillo & \\
\hline Polypadilum & Rojizo & \\
\hline
\end{tabular}

Subfamilia Tanypodinae, Tribu Macropelopiini

\begin{tabular}{|c|c|c|}
\hline Apsectrotanypus & $\begin{array}{c}\text { Marrón, tonalidades } \\
\text { amarillas }\end{array}$ & $\begin{array}{l}\text { Marrón } \\
\text { oscura }\end{array}$ \\
\hline
\end{tabular}

Tribu Pentaneurini

\begin{tabular}{|c|c|c|}
\hline Ablabesmyia & $\begin{array}{c}\text { Amarillo a marrón, } \\
\text { a veces manchas } \\
\text { oscuras }\end{array}$ & \multirow{3}{*}{ Marrón } \\
\hline Krenopelopia & Claro & \\
\hline Labrundinia & Claro & \\
\hline Larsia & Claro & $\begin{array}{c}\text { Amarilla o } \\
\text { marrón }\end{array}$ \\
\hline Monopelopia & $\begin{array}{l}\text { Verde claro a } \\
\text { amarillento }\end{array}$ & Amarilla \\
\hline Pentaneura & Marrón oscuro & \multirow{3}{*}{ Marrón } \\
\hline Zavrelimyia & $\begin{array}{c}\text { Amarillo a marrón, } \\
\text { manchas oscuras }\end{array}$ & \\
\hline Rheopelopia & Amarillo claro & \\
\hline \multicolumn{3}{|c|}{ Tribu Procladiini } \\
\hline Djalmatista & & $\begin{array}{l}\text { Amarilla } \\
\text { clara }\end{array}$ \\
\hline \multicolumn{3}{|c|}{ Subfamilia Podonominae, Tribu Podonomin } \\
\hline Podonomus syn. & \multirow{2}{*}{ Azul-grisáceo } & \multirow{2}{*}{$\begin{array}{l}\text { Marrón } \\
\text { oscuro }\end{array}$} \\
\hline Parochlus* & & \\
\hline Parochlus & Amarillo & Amarilla \\
\hline \multicolumn{3}{|c|}{ Subfamilia Diamesinae tribe Heptagiini* } \\
\hline Paraheptagyia & Amarillo C & \\
\hline
\end{tabular}

ISSN 1900-4699 • Volumen 11 • Número 1 • Páginas 48-67 • 2015 
acentuada que en los adultos, y el desconocimiento de la autoecología de la mayoría (Raunio et al. 2007). Es evidente que aún falta profundizar en las identificaciones de las larvas empleando caracteres morfológicos, pues en claves recientes, como la de géneros de Chironomidae de Prat et al. (2011), se aclara que debe usarse con cautela, por ser preliminar, y porque ha sido diseñada para ríos sobre los $2500 \mathrm{~m}$ de los Andes entre Colombia y Perú. Otro aspecto es el de las muy variadas y frecuentes deformidades que pueden sufrir las larvas de Chironomus en ambientes contaminados con metales pesados (Barnden 2005), y que eventualmente conducirían a confusión en las identificaciones. En el río Bogotá, con alta contaminación de este tipo, en especial en el trecho Zipaquirá-Chía, que incluye el meandro del Campus UMNG (Quintero \& Wilson 2010), no se ha explorado este tema.

Las dificultades de identificación específica y aún genérica son reconocidas desde hace dos décadas (e. g., Pinder 1983), así que cada vez más se debe recurrir a la taxonomía integrativa, que involucra los caracteres taxonómicos externos y análisis moleculares (Kim et al. 2012, Anderson et al. 2013). Recientemente se ha secuenciado el primer genoma complete de un quironómido (Belgica antarctica) (Kelley et al. 2014).

Las limitaciones taxonómicas y de conocimiento ecológico son más acentuadas en países de los Andes tropicales (Ruiz et al. 2000, Acosta 2009, Acosta et al. 2009), como Colombia, donde no se ha profundizado mucho en su estudio, menos aún en el río Bogotá, en especial en el meandro evaluado.

\section{Composición del grano del sedimento}

La composición del sustrato en todo el tramo del río estudiado fue homogénea. En los tres lugares predominaron la arena fina y el limo (Fig. 2).

La composición del sedimento en aguas del meandro es muy similar a otros trechos del río y está dada por la alta carga sedimentaria proveniente del lavado de suelos y desintegración de lodos causada por actividades minerías y agrícolas (CAR 2009). Lo anterior también es distintivo de otros grandes ríos colombianos, como el Cauca (Ramírez et al. 2004), e incluso mucho más pequeños, como el Gaira (Magdalena) (Rodríguez 2011).

El sustrato arenoso-limoso es característico de ríos con llanura aluvial y un contenido alto de materia orgánica (Zilli \& Gagneten 2005), como el río Bogotá (DNP \& MAVDT 2004), y ayuda a explicar la presencia de Chironomidae en el meandro del río Bogotá del Campus UMNG, pues es propicio para larvas y pupas, porque les facilita enterrarse (Cranston 2004, Ferrington 2008, Orendt 2011).

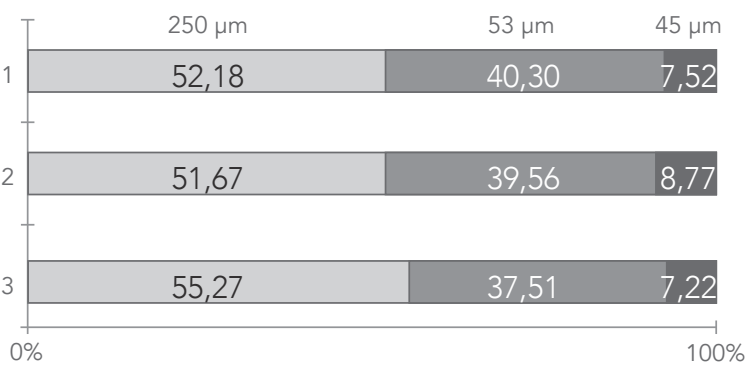

Figura 2. Composición granulométrica (Udden-Wentworth) (Paramo et al. 2012) en los tres lugares y en general en el tramo del río Bogotá, Campus UMNG.

\section{Precipitaciones}

La segunda mitad de 2010 y los primeros meses de 2011 estuvieron caracterizados por uno de los cuatro eventos La Niña más severos desde 1900. En tales casos ocurre una pluviosidad extrema e inundaciones generalizadas, como aconteció en otras partes del mundo (van den Honert \& McAneney 2011, Gloor et al. 2013, Lavado \& Espinoza 2014) y en Colombia, donde las lluvias superaron los promedios anuales de los últimos veinte años (IDEAM 2011) 
En la Sabana de Bogotá La Niña ocasiona descensos de temperatura y aumentos de los volúmenes de precipitación hasta en más del $60 \%$ de su promedio multianual, así como inundaciones en las partes bajas, en especial en las zonas ribereñas de los ríos Bogotá, Tunjuelo y San Cristóbal (Pabón \& Torres 2007).

En el área de Cajicá llovió copiosamente en el periodo febrero-mayo de 2011, lo que ocasionó inundaciones, especialmente durante marzo y abril, por la topografía del terreno, el nivel freático donde existen asentamientos humanos, el rebosamiento de canales y el desbordamiento de ríos como el Bogotá y el Frío (Alcaldía de Cajicá 2012). En dicho periodo las lluvias sobrepasaron los $90 \mathrm{~mm}$, alcanzando 239, $9 \mathrm{~mm}$ en abril, para disminuir a apenas
1,4 mm en septiembre. En el meandro del río Bogotá del Campus UMNG también fue patente el evento, pues el 29 de marzo se registró el máximo de lluvias $(46,3 \mathrm{~mm})$ y entre abril y junio inundaciones que impidieron la toma de datos y muestras en los sectores evaluados (Fig. 3). Lo anterior es consecuente con el hecho de que en Colombia, por lo general, las correlaciones entre los índices máximos del ENOS y los caudales fluviales se producen por un lapso de tres meses (Gutiérrez \& Dracup 2001, Poveda et al. 2010).

\section{Variables limnológicas}

La temperatura osciló según corresponde a la época del año, mientras que la transparencia y los
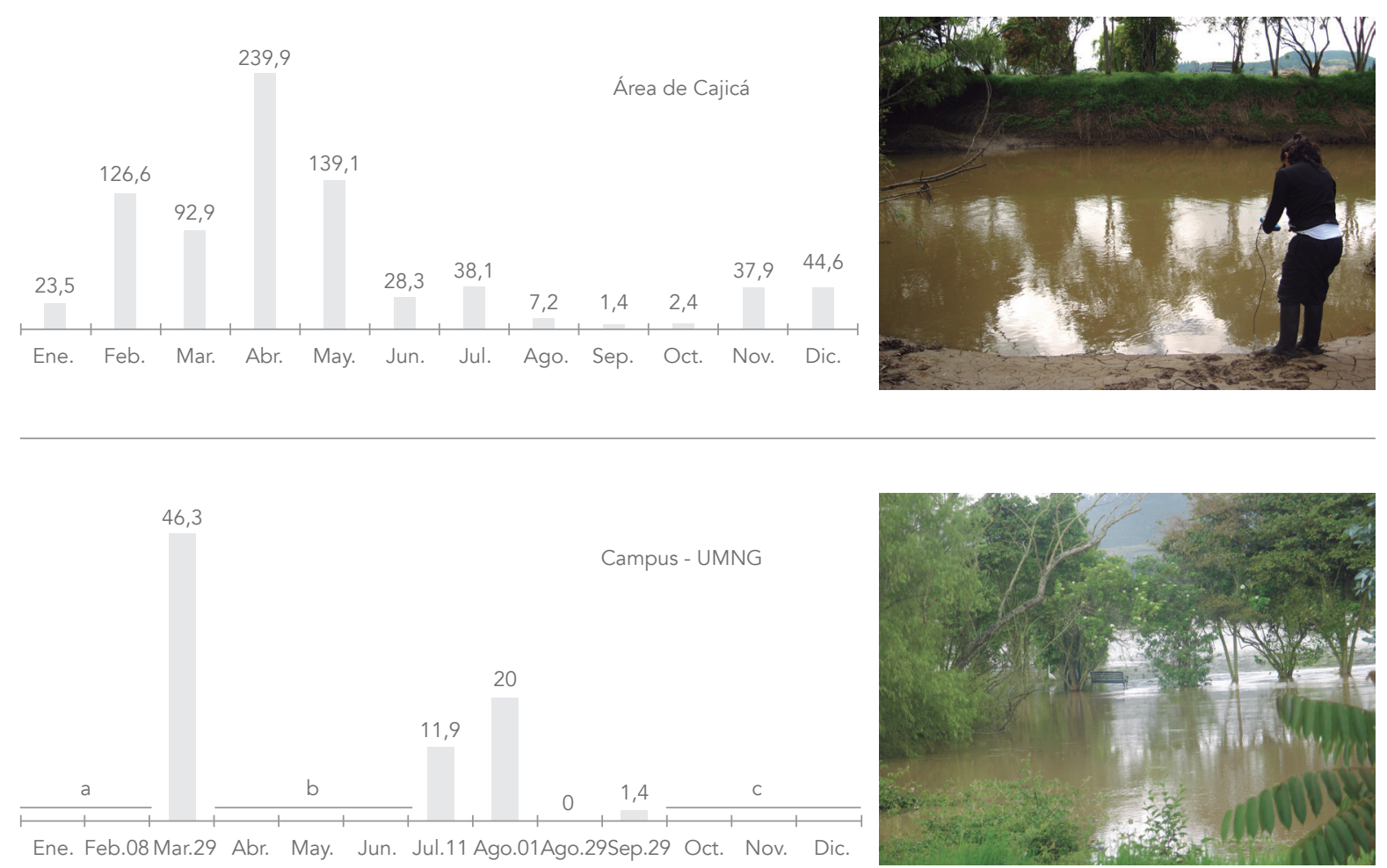

Figura 3. Variación mensual de las precipitaciones $(\mathrm{mm})$ y en las fechas de muestreo en 2011. a, b y c. Datos no disponibles. b. Inundación en el área de estudio por efecto de La Niña. Fotografías G. M. Talero. 
sólidos variaron cronológicamente con las precipitaciones, de manera inversa (Tabla 1), por el aumento de detritus orgánico y los sólidos de procesos erosivos (APHA et al. 2005). Esta situación se reflejó en los sólidos totales en los tres sectores, que excedieron la concentración en aguas de la región Andina (10-200mg/l) (Roldán \& Ramírez 2008), y aumentaron los procesos de descomposición y el consumo de $\mathrm{O}_{2}$ (Riss et al. 2002b), como se observó al comienzo de 2011.

Las aguas tendieron a ser blandas (ligeramente ácidas $\mathrm{pH}<7$, dureza $<60 \mathrm{mg} / \mathrm{l}$ ), similares a los de varias quebradas y ríos andinos $(\mathrm{pH} 6,5-7,5)$ (Roldán \& Ramírez 2008), mientras que la conductividad correspondió a aguas normales $\left(50-350 \mu \mathrm{Scm}^{-1}\right)$ (APHA et al. 2005).

Los compuestos de nitrógeno y fósforo también respondieron, en mayor o menor medida, a la dinámica hídrica generada por la pluviosidad e indicaron contaminación alta relacionada con químicos agrícolas llevados al agua por escorrentía y las inundaciones en 2011, lo cual implicó mayor eutrofización del río. Situaciones análogas se han observado en otros sistemas lóticos colombianos (e. g., Ramírez et al. 2004, Sánchez 2005, García et al. 2007, Rodríguez et al. 2007, Bustamante et al. 2008, Walteros \& Paiba 2010). Los promedios de $\mathrm{NO}_{3}$ - fueron más elevados que los de otros tramos del río Bogotá (2,7 mg/l) (Roldán \& Ramírez 2008).

Según Roldán (1992) en los sistemas lóticos el $\mathrm{Fe}^{2+}$ también aumenta con las precipitaciones, como en el río Villeta (Cundinamarca) (9,2 mg/l) (Ruiz \& Rincón 2014). Esto no se evidenció en el área de estudio en 2011, pues no sobrepasó 0,9mg/l, concentración muy baja comparada con los ríos Magdalena y Cauca (5,0- 6,0 mg/l) (Roldán \& Ramírez 2008). En años anteriores, Quintero \& Wilson (2010) midieron entre 1,6 y $6,5 \mathrm{mg} / \mathrm{l}$ en el curso del río Bogotá por la Sabana de Bogotá, con 1,2-3,7 mg/l en el tramo Zipaquirá-Chía, i. e., pasando por el meandro del Campus UMNG.
En cuanto a los efectos del $\mathrm{Fe}^{2+}$ sobre las comunidades de macroinvertebrados bentónicos, Barnden (2005) observó que el hierro precipitado afectó la abundancia, más que la composición, en la que predominaron Orthocladiinae y Deleatidium (Ephemeroptera). El hierro floculado mostró menor impacto sobre tales comunidades.

\section{Relación N/P y estado trófico del meandro.}

La dinámica de nutrientes es importante en los cuerpos de agua, porque define su productividad y el grado o estado trófico (aumento de la concentración de nutrientes por el vertimiento de residuos sólidos y líquidos derivados de actividades antropogénicas), el cual se incrementa progresivamente en función del caudal, el aporte del flujo de entrada, y la capacidad de resiliencia de los ecosistemas acuáticos. Como consecuencia se dan diferentes cambios en la dinámica de los cuerpos de agua que se reflejan en la relación N/P (Roldán 1996, Roldán \& Ramírez 2008), la cual fluctuó en el meandro del río Bogotá a lo largo del periodo de estudio, con incrementos luego de los picos de lluvia e indicó aguas eutróficas con tendencia a la hipertrofia (Fig. 4). Estos procesos son corrientes y se relacionan con la contaminación por materia orgánica, producto de varias fuentes, como las aguas residuales e industriales vertidas al río (DNP \& MAVDT 2004).

En febrero se produjeron estados tróficos diferentes por sector: 1. Mesotrófico, 2. Eutrófico, 3. Hipertrófico, quizás por acumulación de la carga de $\mathrm{N}$ y $\mathrm{P}$ en el gradiente longitudinal, como resultado de las menores precipitaciones. Ante la falta de dato para ese mes en Cajicá, se obtuvo el de Zipaquirá (23.5 ml) cercano al meandro estudiado, según se explicó en la metodología.

La presencia de Chironomidae indica aguas muy contaminadas, mesotróficas a hipertróficas, aún en aguas moderadamente contaminadas, a veces con abundancias de hasta miles de individuos, (Roldán 
Tabla 2. Datos abióticos en los sectores de estudio del meandro del río Bogotá Campus UMNG durante 2011. Pre= precipitaciones, Tra= transparencia, $\mathrm{SS}=$ sólidos suspendidos, $\mathrm{SD}=$ sólidos disueltos, $\mathrm{ST}=$ sólidos totales, Con= conductividad, $\mathrm{Tem}=$ temperatura, $\mathrm{DT}=$ dureza total. ${ }^{*} \mathrm{no}$ determinado.

\section{Sector 1}

\begin{tabular}{|c|c|c|c|c|c|c|c|c|c|c|c|c|c|c|c|c|}
\hline & $\begin{array}{l}\text { Pre. } \\
\text { mm }\end{array}$ & $\begin{array}{l}\text { Tra. } \\
\text { cm }\end{array}$ & $\begin{array}{c}\mathrm{SS} \\
\mathrm{mg} / \mathrm{l}\end{array}$ & $\mathrm{mg} / \mathrm{l}$ & $\begin{array}{c}\text { ST } \\
\mathrm{mg} / \mathrm{l}\end{array}$ & $\begin{array}{l}\text { Con. } \\
\mu \mathrm{Scm}^{-1}\end{array}$ & $\underset{{ }^{\circ} \mathrm{C}}{\mathrm{Tem}}$ & pH & $\begin{array}{c}\mathrm{O}_{2} \\
\mathrm{mg} / \mathrm{l}\end{array}$ & $\mathrm{mg} / \mathrm{l}$ & $\begin{array}{l}\text { DT } \\
\mathrm{ng} / \mathrm{l}\end{array}$ & $\begin{array}{l}\mathrm{NH}_{4}^{+} \\
\mathrm{mg} / \mathbf{l}\end{array}$ & $\begin{array}{l}\mathrm{NO}_{2}^{-} \\
\mathrm{mg} /\end{array}$ & $\begin{array}{l}\mathrm{NO}_{3}^{-} \\
\mathrm{mg} / 1\end{array}$ & $\begin{array}{l}\mathrm{PO}_{4}^{3-} \\
\mathrm{mg} / \mathrm{l}\end{array}$ & \\
\hline & $\star$ & 3.9 & * & * & * & & & & & & & & & & 4 & \\
\hline & 46.3 & 1 & 0.0 & 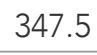 & 7.5 & & & & & & & & & & & \\
\hline & 10 & 44.0 & 0 & & & 21 & & & 6 & & & & & & & 9.1 \\
\hline & 2 & 13.0 & & & & & & & & & & & & & & \\
\hline & 0.0 & 260 & 60.0 & 126 & 86.5 & & 17.0 & & 5 & & 2 & & & & & 06 \\
\hline & 1.4 & 01.0 & 100.0 & 236.0 & 336.0 & & 11.0 & & & & & & & & & 1. \\
\hline & 13.3 & 26.3 & 230.0 & 152.7 & 382.7 & 353.8 & 16.9 & & & & & & & ? & 1 & 6. \\
\hline & 1.4 & $r_{1}$ & 1.2 & 0.8 & .9 & & . & 0.1 & 0.0 & 0.1 & 0.0 & 0.0 & 0.1 & 0.6 & 1.2 & 0.4 \\
\hline
\end{tabular}

\section{Sector 2}

\begin{tabular}{ccccccccccccccccc} 
08.Feb.11 & $*$ & 34.3 & $*$ & $*$ & $*$ & 360.0 & 17.7 & 6.8 & 0.5 & 0.0 & 2.2 & 1.0 & 0.1 & 4.0 & 1.1 & 4.7 \\
\hline 29.Mar.11 & 46.3 & 21.7 & 140.0 & 340.0 & 480.0 & 680.0 & 17.9 & 6.6 & 1.8 & 0.4 & 3.0 & 3.1 & 0.1 & 4.0 & 4.4 & 1.6 \\
\hline 11.Jul.11 & 11.9 & 35.3 & 480.0 & 109.5 & 589.5 & 219.0 & 16.9 & 6.6 & 7.1 & 0.4 & 1.4 & 0.5 & 0.1 & 4.0 & 0.7 & 6.6 \\
\hline 01.Ago.11 & 20.0 & 13.5 & 40.0 & 97.0 & 137.0 & 194.0 & 16.0 & 6.2 & 7.8 & 0.5 & 1.8 & 1.4 & 0.1 & 0.4 & 0.7 & 2.7 \\
\hline 29.Ago.11 & 0.0 & 30.0 & 100.0 & 109.0 & 209.0 & 218.0 & 16.8 & 5.2 & 5.6 & 0.4 & 2.2 & 0.7 & 0.2 & 4.0 & 0.7 & 6.9 \\
\hline 26.Sep.11 & 1.4 & 28.0 & 140.0 & 174.5 & 314.5 & 349.0 & 18.1 & 6.8 & 7.4 & 0.3 & 2.8 & 0.4 & 0.0 & 1.0 & 0.4 & 3.6 \\
\hline Promedio & 13.5 & 27.1 & 150.0 & 138.3 & 288.3 & 336.7 & 17.2 & 6.4 & 5.0 & 0.3 & 2.2 & 1.2 & 0.1 & 2.9 & 1.3 & 4.4 \\
\hline CV & 1.4 & 0.3 & 1.1 & 0.8 & 0.8 & 0.5 & 0.0 & 0.1 & 0.6 & 0.5 & 0.3 & 0.9 & 0.4 & 0.6 & 1.1 & 0.5
\end{tabular}

\section{Sector 3}

\begin{tabular}{ccccccccccccccccc}
\hline 08.Feb.11 & $*$ & 34.0 & $*$ & $*$ & $*$ & 325.0 & 18.8 & 6.7 & 0.9 & 0.0 & 1.8 & 0.1 & 0.1 & 4.0 & 2.6 & 1.6 \\
\hline 29.Mar.11 & 46.3 & 27.9 & 140.0 & 359.0 & 499.0 & 718.0 & 17.9 & 7.0 & 1.9 & 0.4 & 2.5 & 0.5 & 0.0 & 4.0 & 4.4 & 1.0 \\
\hline 11.Jul.11 & 11.9 & 32.8 & 420.0 & 117.0 & 537.0 & 234.0 & 15.8 & 6.3 & 6.2 & 0.3 & 2.0 & 0.5 & 0.0 & 9.0 & 0.6 & 15.9 \\
\hline 01.Ago.11 & 20.0 & 14.0 & 80.0 & 99.5 & 179.5 & 199.0 & 15.2 & 6.7 & 7.2 & 0.6 & 2.1 & 5.0 & 0.4 & 4.0 & 1.4 & 6.7 \\
\hline 29.Ago.11 & 0.0 & 32.0 & 60.0 & 139.0 & 199.0 & 278.0 & 16.7 & 6.2 & 6.1 & 0.2 & 2.2 & 1.9 & 0.2 & 5.0 & 0.7 & 10.1 \\
\hline 26.Sep.11 & 1.4 & 38.0 & 80.0 & 156.0 & 236.0 & 312.0 & 17.7 & 6.4 & 6.1 & 0.7 & 2.6 & 0.4 & 0.0 & 1.4 & 0.7 & 2.6 \\
\hline Promedio & 13.3 & 29.8 & 130.0 & 145.1 & 275.1 & 344.3 & 17.0 & 6.6 & 4.8 & 0.4 & 2.2 & 1.4 & 0.1 & 4.6 & 1.7 & 6.3 \\
\hline CV & 1.4 & 0.3 & 1.1 & 0.8 & 0.7 & 0.5 & 0.1 & 0.04 & 0.6 & 0.7 & 0.1 & 1.3 & 1.2 & 0.5 & 0.9 & 0.9 \\
\hline
\end{tabular}




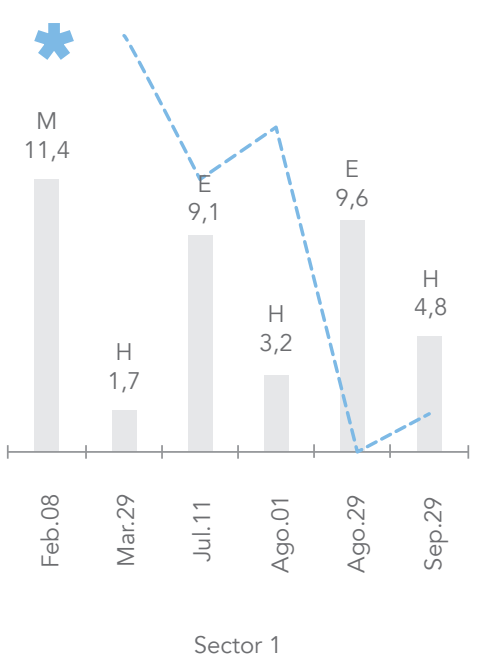

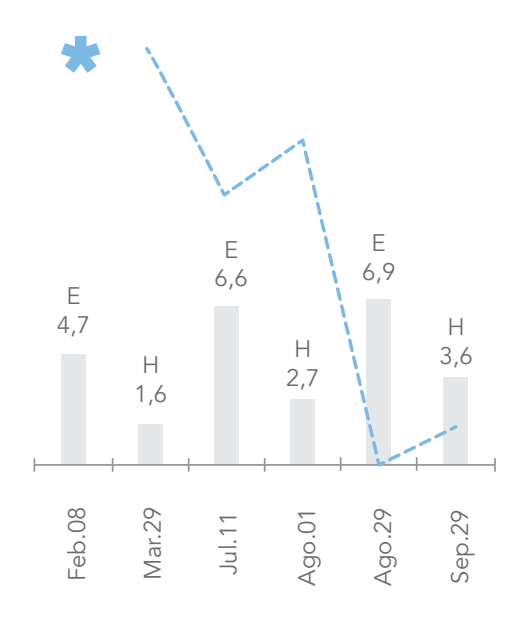

Sector 2

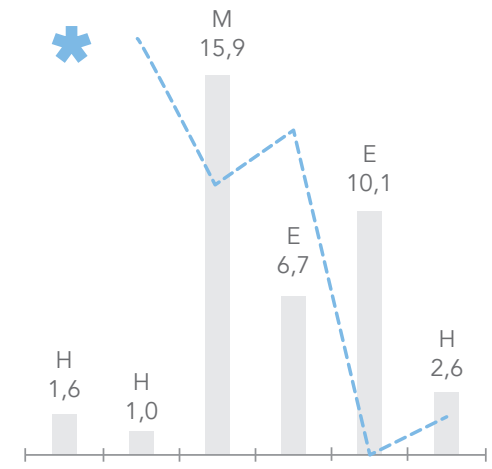

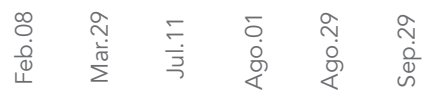

Sector 3

Figura 4. Tendencia del grado trófico (N/P) en aguas del meandro del río Bogotá, Campus UMNG. M= Mesotrófico, E= Eutrófico, H= Hipertrófico. --- precipitaciones. ( ${ }^{\star}$ dato no disponible).

1996, Zilli \& Gagneten 2005, Camargo \& Alonso 2007), en razón de su tasa reproductiva alta (Segnini 2003). Dentro de la familia, uno de los géneros que mejor se la eutrofización es Chironomus (Coffman y Ferrington 1996), lo que aumentaría las probabilidades de hallarlo con predominancia en aguas del río Bogotá, pues ambientes oligotróficos suelen tener una estructura de las poblaciones de Chironominae más vasta, con presencia de una gama más amplia de géneros y subfamilias, como Tanypodinae, indicadora de ambientes estables (Coffman \& Ferrington 1996), lo cual no fue el caso del río Bogotá estudiado.

\section{Densidad de Chironomidae}

En los tres sectores se observó una variación cronológica marcada, atribuida en primera instancia a la influencia de las precipitaciones, cuyo valor más alto en marzo coincidió con las mayores densidades de las larvas de Chironomidae en los sectores 1 y 2 . Como se anotó en esa fecha el agua tendió a la hipertrofización, por el gran aumento de la carga de $\mathrm{N}$ y P.
En los meses posteriores, con condiciones eutróficas e incluso mesotróficas en dos fechas/sectores, la relación fue contraria, excepto en el sector 3 en septiembre (hipereutrofizado), cuando se registró el número más alto allí, pese a las lluvias exiguas (Fig. 5). Estas variaciones de densidad son usuales, pues las larvas de Chironomidae pueden predominar, tanto en épocas de alta como de baja precipitación, como los ríos: Grande (Argentina) (Medina \& Paggi 2004), Ribeirão da Quinta (Brasil) (Ribeiro \& Uieda 2005), Sensunapán (Salvador) (Chávez \& Orantes 2010), Santa Lucía (Uruguay) (Chalar et al. 2011) y Negro (Colombia) (Montoya et al. 2011, Chironomus; Forero et al. 2014).

Los promedios por sector indicaron semejanza entre los tres sectores, i. e., alguna homogeneidad cuantitativa, explicada por su reconocida ubicuidad en un amplio rango de nichos ecológicos y a lo largo del gradiente de calidad del agua (Gutiérrez et al. 2004). En todo caso, debe observarse que la composición y biomasa suelen variar a lo largo de los 


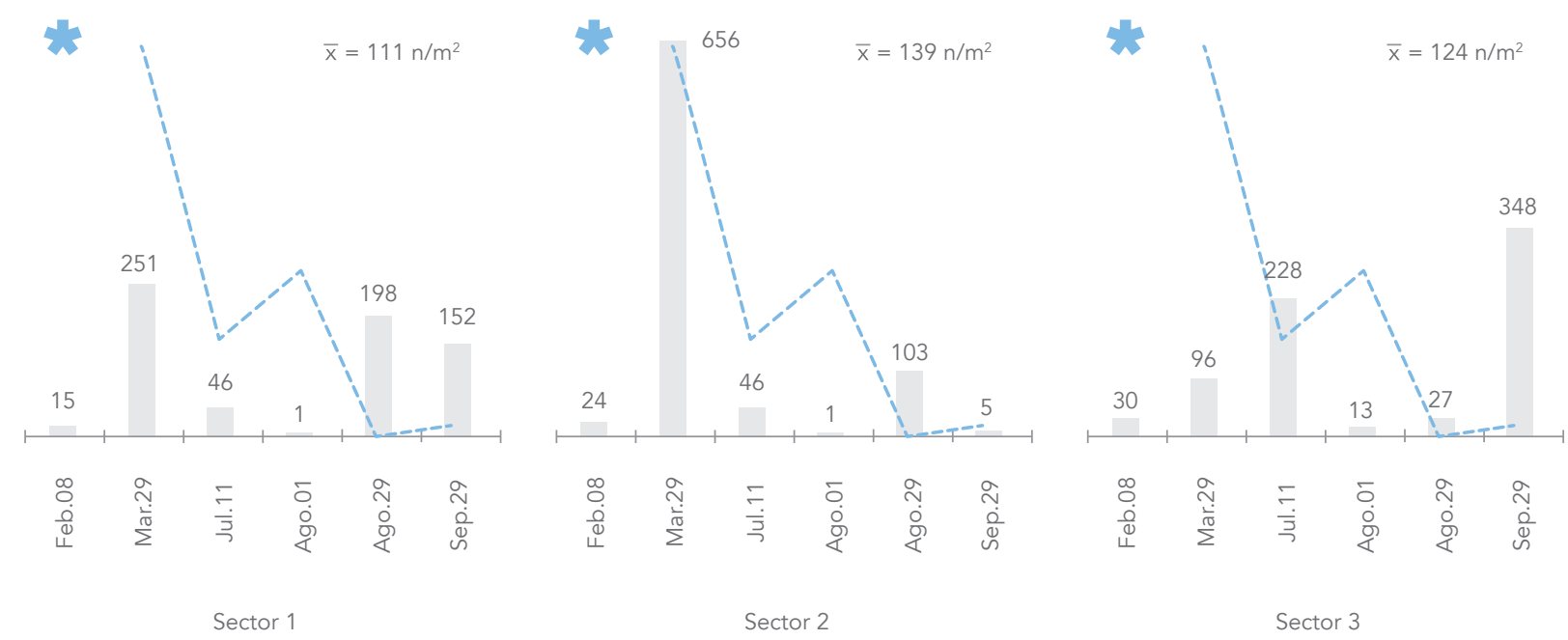

Figura 5. Densidad larval de Chironomidae $\left(\mathrm{n} / \mathrm{m}^{2}\right)$ en el meandro del río Bogotá, Campus UMNG. ---- precipitaciones (* dato no disponible).

sistemas fluviales (Galizzi et al. 2012, Butakka et al. 2014, Rosa et al. 2014), y que los muestreos en un solo hábitat (sector) difícilmente revelan la verdadera composición de las comunidades a través del continuo de un río, como denotan Rodríguez et al. (2007).

Tal vez haya reparos sobre los datos de densidad obtenidos en el meandro del río Bogotá evaluado, pues se efectuaron tres replicas por unidad muestral, como métodos estándar en evaluaciones rápidas de macroinvertebrados bentónicos fluviales (Barbour et al.1999). Sobre el número de réplicas se ha discutido mucho; por ejemplo, Oyague (2009) afirma que "muestreos con esfuerzos por debajo de las 12 unidades muestrales y muestras individuales constituidas por cinco o menos réplicas, aportan datos muy poco confiables para estimar la densidad". Empero, el trabajo se basó en aproximaciones empíricas de la densidad en algunos ecosistemas lóticos del Perú, las cuales se compararon con datos del río Colorado del mismo país; aunque se valoraron 20 unidades muestrales y 15 réplicas/estación, sólo se cubrieron ca. $2 \mathrm{~km}$ del cauce y la primera quincena de abril de 2009 (final de la época lluviosa).

Lo anterior también estaría en entredicho, por lo mencionado ya con respecto a la multiplicidad de metodologías empleadas en las prospecciones de este tipo de comunidades y las diferencias notorias en la gran variedad de ecosistemas acuáticos estudiados.

La incertidumbre sobre la pertinencia en el cotejo se extiende al meandro del río Bogotá Campus UMNG. En el único estudio previo sobre macroinvertebrados bentónicos (marzo-octubre 2009), aunque con la misma red Surber, sólo se obtuvieron dos réplicas en dos sectores, uno de ellos correspondiente al sector 1 de la presente investigación. Para esa época, el índice BMWP/Col., allí señaló aguas muy contaminadas con mayor abundancia relativa de Tubificidae, mientras que Chironomidae que ocupó el segundo lugar (Gómez \& Contreras 2009).

Ramírez et al. (2013) también aplicaron ese índice en los tres sectores del meandro considerados aquí. La puntuación fue 48,2; 48,3 y 43,0 respectivamente, 
i. e., contaminación moderada y eutrofización, atribuidas a las aguas residuales y actividades agropecuarias; al particularizar en Chironomidae, el valor BMWP/Col., fue 2 en los tres sectores, i. e., agua fuertemente contaminada (calidad crítica) en las seis fechas de muestreo.

Entre febrero y mayo de 2010 (El Niño) en cuatro sectores del río Bogotá en el municipio de Tocancipá (distante ca. $13 \mathrm{~km}$ de Cajicá) la calidad del agua también fue crítica en uno de ellos, alta en otro y baja en el cuarto. Las larvas de Chironomidae sólo contribuyeron con $4,7 \%$ a la comunidad de macroinvertebrados bentónicos (Ochoa \& Castañeda 2010). Algo análogo observaron Forero et al. (2014) en el río Negro, pues Chironomus tuvo una puntuación de 4,4 con el Índice de Calidad Ecológica (ICE $\left.E_{\text {RN-MAE }}\right)$, i. e., también condiciones críticas.

No obstante, se estima que el índice BMWP/ Col., tiene varias restricciones: se desarrolló para una zona de Antioquia, obviando la gran diversidad geográfica de Colombia y la abundancia/biomasa; al considerar sólo el nivel de familia se ignora la variación de los rangos de tolerancia de los géneros/especies dentro una misma familia. Ante esta situación, se han planteado como alternativas el Índice de Calidad del Agua (ICA), Promedio de Puntuación por Taxón (ASPT) (Montoya et al. 2011) y el ICE $E_{\text {RN-MAE' }}$ formulado con base en análisis multivariados (Forero et al. 2014).

La confiabilidad del uso de los quironómidos a nivel de familia, como indicadores de aguas fuertemente contaminadas (Riss et al. 2002a; Roldán, 2003), ha sido rebatida en Colombia por Montoya et al. (2011) y Forero et al. (2014), e incluso en el Mediterráneo (Puntí et al. 2009) y Malasia (Al-Sham et al. 2010), debido a su carácter eurióico, pues aparecen en todo tipo de ecosistemas acuáticos, con aguas de muy buen calidad hasta muy contaminadas y eutrofizadas (Cranston 2000, 2004, Helson et al. 2006, Ferrington 2008, Orendt et al. 2011).

\section{Análisis estadístico}

Los dos primeros ejes del ACP (entre paréntesis autovalores) explicaron el $74.7 \%$ de la varianza de los datos en los sectores 1,2 y 3 respectivamente. Aunque en general las correlaciones fueron $< \pm 0,5$, tal vez por el bajo número de datos, manifestaron asociación con la densidad de larvas y algunas diferencias, sobre todo de los dos primeros sectores con el tercero (Fig. 6). Este resultado fue corroborado por el test K-W (P valor $=0.001$ ) y se atribuyó a la descarga allí de agua con fertilizantes agrícolas y aparente carga elevada de sedimento.

La temperatura y la concentración de $\mathrm{O}_{2}$ se relacionaron de manera inversa, como es común en los ecosistemas acuáticos y determina la dinámica de los quironómidos (Pinder 1986), lo cual se reflejó en la relación de su densidad con esas variables. Los valores medidos en el río Bogotá se encuentran dentro de los que favorecen su reproducción y proliferación (Roldán \& Ramírez 2008). Algo semejante puede aplicarse a las asociaciones con las demás variables que definieron el cuadro limnológico en aguas del meandro.

Aunque las correlaciones con la precipitación fueron bajas, es un hecho que la escorrentía ocasionada produce efectos directos e indirectos sobre los procesos físico-químicos, a veces con mayor impacto en la mineralización, que también afectan la biota acuática (Roldán 1996, Roldán \& Ramírez 2008), lo cual se observó en el meandro del río Bogotá, en general, y al confrontar los tres sectores.

Un aspecto final a considerar es que, en los estudios sobre macroinvertebrados bentónicos, la información sobre sus depredadores y el espectro trófico disponible para su alimentación es muy útil (e. g., Barnden 2005, Galizzi et al. 2012, Butakka et al. 2014). Los hábitos de las larvas de Chironomidae (principalmente detritívoras/sedimentívoras), presuponen un solo grupo funcional con alimento permanente en el meandro del río Bogotá, lo que también favorecería allí el desarrollo del ensamble de esa familia. 


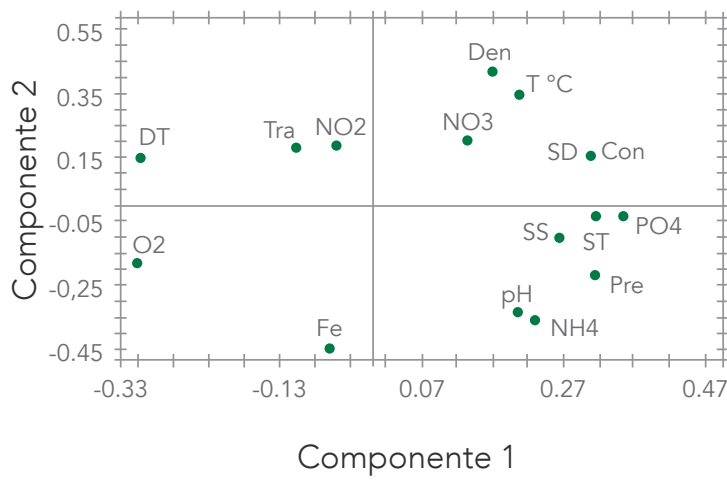

Sector 1

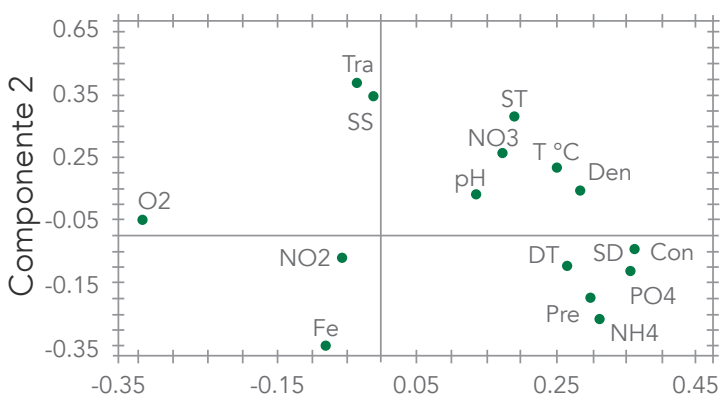

Componente 1

Sector 1

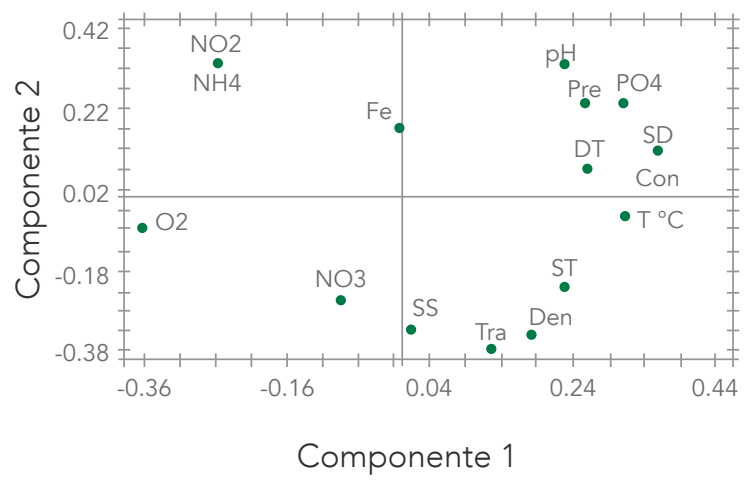

Sector 1

Fig. 6. ACP de la densidad larval de Chironomidae (Den) y las variables abióticas en los tres sectores en el meandro del río Bogotá, Campus UMNG. Pre $=$ precipitaciones, Tra $=$ transparencia, SS= sólidos suspendidos, $\mathrm{SD}=$ sólidos disueltos, $\mathrm{ST}=$ sólidos totales, $\mathrm{Con}=$ conduc tividad, Tem = temperatura, DT= dureza total.
Esta asunción requiere comprobarse llevando las identificaciones a género y especie, en vista de las diferentes preferencias alimentarias y superposición de nicho entre los grupos tróficos de las larvas de Chironomidae en diferentes hábitats, como se ha comprobado en la llanura de inundación de varios ecosistemas neotropicales (Butakka et al. 2014).

Como se ha comprobado en otras regiones, los procesos físico-químicos y la densidad de Chironomidae se ajustaron al pulso del río, determinado por el ciclo de lluvias intensificadas por la Niña 2011. A esta dinámica obedeció la contaminación moderada y estado trófico en aguas del meandro.

Allí, el asentamiento de las larvas de Chironomidae se favorece por estas condiciones y el tipo de sustrato que brinda la posibilidad de una distribución homogénea. Estos aspectos, junto con la evidente presencia de hemoglobina, acaso sirvan para apoyar la suposición inicial de que los ejemplares capturados pudieron corresponder a Chironomus, lo cual debe comprobarse con la taxonomía en estudios posteriores.

Por la complejidad de la familia Chironomidae hace falta emplear en el análisis identificaciones genéricas y específicas, biomasas, índices ecológicos de la calidad del agua, riqueza y diversidad, para establecer algunas características descriptivas de la estructura y organización de esta taxocenosis.

\section{AGRADECIMIENTOS}

Este trabajo es producto del proyecto CIAS 708: Evaluación de la comunidad de macroinvertebrados bentónicos en un sector rural del río Bogotá (Cajicá, Departamento de Cundinamarca), financiado por la Vicerrectoría de Investigaciones de la Universidad Militar Nueva Granada. 


\section{REFERENCIAS}

1. Acosta R, Ríos B, Blanca R, Rieradevall M y Prat N. 2009. Propuesta de un protocolo de evaluación de la calidad ecológica de ríos andinos (CERA) y su aplicación a dos cuencas en Ecuador y Perú. Limnetica, 28 (1): 35-64.

2. Acosta R. 2009. Estudio de la cuenca altoandina del río Cañete (Perú): distribución altitudinal de la comunidad de macroinvertebrados bentónicos y caracterización hidroquímica de sus cabeceras cársticas. Tesis Ph. D., U. de Barcelona, Fac. Biología, Dep. d'Ecologia, Barcelona, 153 p.

3. Aguirre J, Rodríguez J y Ospina R. 2012. Deriva de macroinvertebrados acuáticos en dos sitios con diferente grado de perturbación, río Gaira, Santa Marta-Colombia. Revista Intropica, 7: 9-19.

4. Alcaldía de Cajicá. 2012. Acuerdo No. 05 de 2012. Plan de Desarrollo Municipal (2012-2015), Alcaldía Municipal de Cajicá, 239 p. http://cajica. gov.co/index.php/planeacion-gestion-y-control/ politicas/finish/30-politicas-planes-o-lineasestrategicas/873-acuerdo-05-plan-de-desarrollomunicipal-2012-2015, consulta octubre de 2014.

5. Anderson AM, Stur E y Ekrem T. 2013. Molecular and morphological methods reveal cryptic diversity and three new species of Nearctic Micropsectra (Diptera:Chironomidae). Freshwater Science, 32(3): 892-921.

6. Andreoli RV y Kayano M T. 2005. Enso-related rainfall anomalies in South America and associated circulation features during warm and cold Pacific Decadal Oscillation regimes. International Journal of Climatology, 25: 2017-2030. DOI: 10.1002/joc.1222, consulta octubre de 2014.

7. APHA, AWWA y WPCF. 2005. Standard methods for the examination of water and wastewater. American Public Health Association (APHA), American Water Works Association (AWWA) and Water Environment Federation (WEF), Washington, 1325 p.
8. Barbour M T, Gerritsen J, Griffith G E, Frydenborg R, McCarron E, White J S, Bastian M L. 1996. A framework for biological criteria for Florida streams using benthic macroinvertebrates. Journal of North American Benthological Society, 15: 185-211.

9. Barbour MT, Gerritsen J, Snyder BD y Stribling JB. 1999. Rapid bioassessment protocols for use in streams and wadeable rivers: Periphyton, benthic macroinvertebrates and fish, Second Edition. EPA 841-B-99-002. U. S. Environmental Protection Agency, Office of Water, Washington, D.C.

10. Barnden A R. 2005. Ecology of streams affected by iron precipitates and iron flocculants. Tesis $\mathrm{M}$. Sc. Zoología, U. de Canterbury, Canterbury, 134 p. http://www.crl.co.nz/downloads/geology/Barnden\%20MSc.pdf, consulta octubre de 2014.

11. Bernal E., D. García, M. A. Novoa \& A. Pinzón. 2006. Caracterización de la comunidad de macroinvertebrados de la quebrada Paloblanco de la cuenca del río Otún (Risaralda, Colombia). Acta Biológica Colombiana, 11(2): 45-59.

12. Bustamante CA, Monsalve E y García PL. 2008. Análisis de la calidad del agua en la cuenca media del río Quindío con base en índices físicos, químicos y biológicos. Revista de Investigaciones Universidad del Quindío, 18: 22-31.

13. Butakka CM, Ragonha FH y Takeda AM. 2014. Chironomidae larvae (Diptera) of Neotropical floodplain: overlap niche in different habitats. Brazilian Journal of Biology, 74(2): 363-370

14. Camargo J y Alonso A. 2007. Contaminación por nitrógeno inorgánico en los ecosistemas acuáticos: Problemas medioambientales, criterios de calidad del agua, e implicaciones del cambio climático. Ecosistemas, 2: 1-13.

15. CAR. 2009. Río Bogotá. Adecuación hidráulica y recuperación ambiental. Corporación Autónoma Regional (CAR), Bogotá, D. C., 157 p. 
16. Chalar G, Arocena R, Pacheco JP y Fabián D. 2011. Trophic assessment of streams in Uruguay: A Trophic State Index for Benthic Invertebrates (TSIBI). Ecological Indicators, 11, 362-369.

17. Chávez JM y Orantes EE. 2010. Reconocimiento de las comunidades de macroinvertebrados acuáticos como alternativa para determinar la calidad del agua del Río Sensunapán, Dep. Sonsonate, El Salvador, C.A. Tesis Ingeniero Agrónomo, Fac. Ciencias Agronómicas, Dep. Protección Vegetal San Salvador, U. de El Salvador, San Salvador, 113 p.

18. Choi J, Roche Hy Caquet T. 2001. Hypoxia, hyperoxia and exposure to potassium dichromate or fenitrothion alter the energy metabolism in Chironomus riparius Mg. (Diptera: Chironomidae) larvae. Comparative Biochemistry and Physiology, 130(1): 11-17.

19. Coffman WP y Ferrington LC. 1996, p. 635-754. Chironomidae. En: Merritt RW y Cummins KW (Eds.) An Introduction to the Aquatic Insects of North America. $3^{\text {ra }}$. Ed. Kendall/Hunt Publishing Company, Dubuque.

20. CORPONARIÑO, Alcaldía de Pasto \& U. de Nariño. 2014. Plan de ordenamiento y manejo de la microcuenca Barbero, Cuenca alta del río Pasto, Municipio de Pasto. Corporación Autónoma Regional de Nariño (CORPONARIÑO), Secretaria de Gestión y Saneamiento Ambiental-Alcaldía de Pasto. Universidad de Nariño-Grupo de Estudios y Acciones Ambientales (GREDA), Pasto, 88 p. www. pasto.gov.co, consulta noviembre de 2014.

21. Cranston PS. 1988. Allergens of non-biting midges (Diptera: Chironomidae): A systematic survey of chironomid haemoglobins. Medical and Veterinary Entomology, 2(2): 117-127.

22. Cranston PS. 2000. Monsoonal tropical Tanytarsus van der Wulp (Diptera: Chironomidae) reviewed: new species, life histories and significance as aquatic environmental indicators. Australian Journal of Entomology, 39 (3): 103-120.
23. Cranston PS. 2004. Chironomidae, p. 711-735. En: Yule CHM, Yong HS (Eds.). The Freshwater invertebrates of Malaysia and Singapore. Malaysia: Academy of Sciences.

24. Cuda JP, Coon BR, Dao YM y Center TD. 2002. Biology and laboratory rearing of Cricotopus lebetis (Diptera: Chironomidae), a natural enemy of the aquatic weed hydrilla (Hydrocharitaceae). Annals of the Entomological Society of America, 95: 587-596.

25. Day J, Westphal A, Pratt R, Hyfield E, Rybczyk J, Kemp G P, Day J N y Marx B. 2006. Effects of longterm municipal effluent discharge on the nutrient dynamics, productivity, and benthic community structure of a tidal freshwater forested wetland in Louisiana. Ecological Engineering, 27: 242-257.

26. DNP, MAVDT. 2004. Estrategia para el manejo ambiental del río Bogotá. Documento 3320 Consejo Nacional de Política Económica y Social (CONPES). Departamento Nacional de Planeación-Ministerio de Ambiente, Vivienda y Desarrollo Territorial, Bogotá D. C., 44 p.

27. Duque AS. 2013. Evaluación de la calidad ecológica del agua usando macroinvertebrados acuáticos en la parte alta y media de la cuenca del río Felidia, Valle del Cauca-Colombia. Pasantía Administrador Medio Ambiente y Recursos Naturales. U. Autónoma de Occidente, Fac. Ciencias Básicas, Dep. Ciencias Ambientales, Santiago de Cali.

28. Epler JH, Cuda JP y Center TD. 2000. Redescription of Cricotopus lebetis (Diptera: Chironomidae), a potential biocontrol agent of the aquatic weed hydrilla (Hydrocharitaceae). Florida Entomologist, 83: 172-180.

29. Ferrington LC. 2008. Global diversity of non-biting midges (Chironomidae; Insecta-Diptera) in freshwater. Hydrobiología, 595: 447-455.

30. Forcella $M$, Berra E, Giacchini $R$ y Parenti P. 2007. Antioxidant defenses preserve membrane 
transport activity in Chironomus riparius larvae exposed to anoxia. Archives of Insect Biochemistry and Physiology, 65(4): 181-94.

31. Forero LC, Longo M, Ramírez JJ y Chalar G.2014. Índice de calidad ecológica con base en macroinvertebrados acuáticos para la cuenca del río Negro (ICERN-MAE), Colombia. Revista de Biología Tropical, 62 (Suppl. 2): 233-247.

32. Galizzi MC, Zilli F y Marchese M. 2012. Diet and functional feeding groups of Chironomidae (Diptera) in the Middle Paraná River floodplain (Argentina). Iheringia, Série Zoologia, Porto Alegre, 102(2): 117-121.

33. Gloor M, Brienen RJW, Galbraith D, Feldpausch TR, Schöngart J, Guyot JL, Espinoza JC, Lloyd J y Phillips OL. 2013. Intensification of the Amazon hydrological cycle over the last two decades. Geophysical Research Letters, 40(9): 1729-1733.

34. Gómez M y Contreras A. 2009. Implementación del método BMWP-Colombia para evaluar la calidad del agua del río Bogotá en dos puntos de la Hacienda Rio Grande. Cajicá, Colombia. Proyecto de Iniciación Científica, Prog. Biología Aplicada, Fac. Ciencias, Universidad Militar Nueva Granada, Bogotá D. C., 11 p.

35. Gresens SE, Stur E y Ekrem T. 2012. Phenotypic and genetic variation within the Cricotopus sylvestris species-group (Diptera, Chironomidae), across a Nearctic-Palaearctic gradient. Fauna Norvegica, 31: 137-149.

36. Guevara G, Reinoso G y Villa F. 2006. Comunidad de invertebrados del perifiton del río Combeima (Tolima, Colombia). Revista Tumbaga, 1: 43-54.

37. Guryev V, Makarevitch I, Blinov A y Martin J. 2001. Phylogeny of the genus Chironomus (Diptera) inferred from DNA sequences of mitochondrial cytochrome $b$ and cytochrome oxidase I. Molecular Phylogenetics and Evolution, 19(1):9-21.

38. Gutiérrez F y Dracup JA. 2001. An analysis of feasibility of long-range streamflow forecasting for
Colombia using El Niño-Southern Oscillation indicators. Journal of Hydrology, 246: 181-196. doi: 10.1016/S0022-1694(01)00373-0, consulta noviembre de 2014.

39. Gutiérrez J, Riss W. y Ospina R. 2004. Lógica difusa como herramienta para la bioindicación de la calidad del agua con macroinvertebrados acuáticos en la sabana de Bogotá-Colombia. Caldasia, 26 (1): 161-172.

40. Ha M y Choi J 2008. Effects of environmental contaminants on hemoglobin of larvae of aquatic midge, Chironomus riparius (Diptera: Chironomidae): A potential biomarker for ecotoxicity monitoring. Chemosphere, 71: 1928-1936.

41. Hanson P, Springer M y Ramírez A. 2010. Capítulo 1. Introducción a los grupos de macroinvertebrados acuáticos. Revista de Biología Tropical, 58 (Suppl. 4): 3-37.

42. Helson JE, Williams DD y Turner D. 2006. Larval chironomid community organization in four tropical rivers: human impacts and longitudinal zonation. Hydrobiologia, 559: 413-431.

43. Hoyos N, Escobar J, Restrepo JC, Arango AM y Ortiz J.C. 2013. Impact of the 2010-2011 La Niña Phenomenon in Colombia, South America: The human toll of an extreme weather event. Applied Geography, 39: 16-25.

44. IDEAM, PNUD, Alcaldía de Bogotá, Gobernación de Cundinamarca, CAR, CORPOGUAVIO, Instituto Alexander von Humboldt, Parques Nacionales Naturales de Colombia, MADS, DNP. 2014. Evolución de precipitación y temperatura durante los fenómenos el Niño y la Niña en Bogotá - Cundinamarca. Plan Regional Integral de Cambio Climático para Bogotá Cundinamarca (PRICC), Bogotá, 16 p.

45. Ivleva I.V. 1969. Mass cultivation of invertebrate: Biology and methods. Academy of Science of the URS S. All union Hydrobiologica Society. Israel Program for the Scientific Translations, $148 \mathrm{p}$. 
46. Kelley JL, Peyton JT, Fiston-Lavier AS, Teets NM, Yee MC, Johnston JS, Bustamante CD, Lee E y Denlinger DL. 2014. Compact genome of the Antarctic midge is likely an adaptation to an extreme environment. Nature Communications | 5:4611 | DOI: 10.1038/ncomms5611 |www.nature.com/naturecommunications, consulta octubre de 2014.

47. Kim S, Song K, Ree Hy Kim W. 2012. A DNA barcode library for Korean Chironomidae (Insecta:Diptera) and indexes for defining barcode gap. Molecules and Cells, 33(1): 9-17.

48. Lavado W y Espinoza JC. 2014. Impact of El Niño and La Niña events on Rainfall in Peru. Revista Brasileira de Meteorologia, 29, 171-182.

49. Laverde A y López RH. 2012. Crecimiento de carpa común (Cyprinus carpio carpio, LINNAEUS, 1758) en jaulas flotantes en un reservorio de Cajicá (Cundinamarca), Colombia. Revista Facultad de Ciencias, 8(2): 268-289.

50. Lee SM, Lee SB, Park CH y Choi J. 2006. Expression of heat shock protein and hemoglobin genes in Chironomus tentans (Diptera, chironomidae) larvae exposed to various environmental pollutants: a potential biomarker of freshwater monitoring. Chemosphere, 65: 1074-1081.

51. Liévano A y Ospina R. 2007. Guía ilustrada de los macroinvertebrados acuáticos del río Bahamón. U. El Bosque e Inst. Alexander von Humboldt. Bogotá D.C., $130 \mathrm{p}$.

52. Liévano A. 2013. Calidad biológica de las aguas superficiales de la cuenca del río Apulo. Revista de Tecnología, 12(2): 60-71.

53. Lozano L. 2005. La bioindicación de la calidad del agua: la importancia de los macroinvertebtrados en la cuenca alta del río Juan Amarillo, cerros orientales de Bogotá, Umbral Científico 7: 5-11.

54. Lozano LA. 1995. Utilización de quironómidos (Diptera: Nematocera) como indicadores de contaminación de la parte alta del río Bogotá: evaluación inicial. Trabajo de Grado. U. Nacional de Colombia, Bogotá.

55. Medina Al y Paggi AC. 2004. Composición y abundancia de Chironomidae (Diptera) en un río serrano de zona semiárida (San Luis, Argentina). Revista Sociedad Entomológica Argentina, 63(3-4): 107-118.

56. Montoya Y, Acosta Y y Zuluaga E. 2011. Evolución de la calidad del agua en el río Negro y sus principales tributarios empleando como indicadores los índices ICA, el BMWP/COL y el ASPT. Caldasia, 33(1): 193-210.

57. Navarrete NA, Fernández E y Contreras G. 2004. Abundancia de quironómidos (Diptera: Chironomidae) en el bordo "JC" del norte del Estado de México en el periodo de secas). Hidrobiológica, 14 (2): 157-160.

58. Ochoa N y Castañeda J. 2010. Evaluación comparativa de la comunidad de macroinvertebrados en cuatro puntos de la cuenca alta del río Bogotá (Tocancipá, Cundinamarca). Proyecto de Iniciación Científica, Prog.BiologíaAplicada, Fac.Ciencias, Universidad Militar Nueva Granada, Bogotá D. C., 30 p.

59. Oh JT, Epler JH y Bentivegna CS. 2014. A rapid method of species identification of wild chironomids (Diptera: Chironomidae) via electrophoresis of hemoglobin proteins in sodium dodecyl sulfate polyacrylamide gel (SDS-PAGE). Bulletin of Entomological Research, 104(5): 639-651. doi: 10.1017/ S0007485314000431, consulta noviembre de 2014.

60. Orendt C, Dettinger-Klemm Ay Spies M. 2011. Identification keys to the larvae of Chironomidae (Diptera) in brackish waters of Germany and adjacent areas. Federal Environment Agency, Berlín, 212 p.

61. Ospina TR, Riss W y Ruíz L. 1999. Guía para la identificación genérica de larvas quironómidos (Diptera: Chironomidae: Orthocladiinae) de la Sabana de Bogotá, p. 363-384. En: Amat G, Andrade MG y Fernández F. (Eds.). Insectos de Colombia, Vol. 
11. Academia Colombiana de Ciencias Exactas, Físicas y Naturales, Bogotá.

62. Oyague E. 2009. Discusión sobre el número de unidades muestrales y tamaño de unidad muestral para la estimación de valores de densidad de macroinvertebrados bentónicos en ambientes lóticos. Ecología Aplicada, 8(1-2): 61-70.

63. Pabón D y Torres G. 2007. Impacto socioeconómico de los fenómenos El Niño y La Niña en la Sabana de Bogotá durante el siglo XX. Cuadernos de Geografía, 16: 81-94.

64. Paggi AC. 2001. Diptera: Chironomidae, p. 167193. En: Guía para la determinación de los artrópodos bentónicos sudamericanos. Fernández H. R. \& E. Domínguez (Eds.). Editorial Universitaria de Tucumán, Serie: Investigaciones de la UNT, Tucumán, Argentina.

65. Papusheva E1, Gruhl MC, Berezikov E, Groudieva T, Scherbik SV, Martin J, Blinov A, Bergtrom G. 2004. The Evolution of SINEs and LINEs in the genus Chironomus (Diptera). Journal of Molecular Evolution, 58(3): 269-79.

66. Paramo J, Espinosa L, Posada B, Núñez S y Benavides S. 2012. Distribución espacial de sedimentos en la región norte del Caribe colombiano. Boletín de Investigaciones Marinas y Costeras, 41(1): 9-28.

67. Petrova NA, Zhirov SV, Harutyunova MVy Harutyunova KV. 2012. Cytotaxonomy and Morphology of Chironomid Larvae(Diptera, Chironomidae) in Armenia. Engineering and Technology, 6(5): 491-495. http:// waset.org/publications/10634/cytotaxonomy-andmorphology-of-chironomid-larvae-diptera-chironomidae-in-armenia, consulta octubre de 2014.

68. Pinder LCV. 1983. The larvae of Chironomidae (Diptera) of the Holartic region-Introduction. Entomolical Scandinavian Supplement, 19: 7-10.

69. Pinder LCV. 1986. Biology of freshwate chironomidae. Annual Review Entomologie, 31: 1-23.

70. Posada J, Abril G y Parra L. 2008. Diversidad de los macroinvertebrados acuáticos del páramo de
Frontino (Antioquia, Colombia). Caldasia, 30 (2): 441-455.

71. Poveda G, Álvarez DM y Rueda Ó A. 2010. Hydroclimatic variability over the Andes of Colombia associated with ENSO: a review of climatic processes and their impact on one of the Earth's most important biodiversity hotspots. Climate Dynamics, 36, 2233-2249. doi: 10.1007/s00382-010-0931-y, consulta octubre de 2014.

72. Prat N, González JD y Ospina R. 2014. Clave para la determinación de exuvias pupales de los quironómidos (Diptera: Chironomidae) de ríos altoandinos tropicales Revista de Biología Tropical, 62 (4): 1385-1406.

73. Prat N, Rieradevall M, Acosta R y Villamarín C. 2011. Guía para el reconocimiento de las larvas de Chironomidae (Diptera) de los ríos altoandinos de Ecuador y Perú. Clave para la determinación de los géneros. Grupo de Investigación F.E.M. Departamento de Ecología, Universidad de Barcelona, Barcelona, 78 p.

74. Quintero DH y Wilson JC. 2010. Prediagnóstico toxicológico asociado al recurso agua de la cuenca alta del río Bogotá. Proyecto de grado Ingeniera Ambiental y Sanitaria. U. de La Salle, Fac. Ingeniería, Bogotá, 92 p.

75. Ramírez C, García J, Ramírez O y Bocanegra R. 2004. Caracterización de los materiales del lecho del río Cauca. Facultad de Ingeniería, Universidad del Valle. Ingeniería, Recursos Naturales y Ambiente, 1(1):10-17.

76. Ramírez D, Talero G y López R. 2013. Macroinvertebrados bentónicos y calidad del agua en un tramo del río Bogotá. Cajicá-Colombia. Revista U.D.C.A. Actualidad \& Divulgación Científica, 16(1): 205-214.

77. Raunio J, Paavola R y Muotka T. 2007. Effects of emergence phenology, taxa tolerances and taxonomic resolution on the use of the chironomid pupal exuvial technique in river biomonitoring. Freshwater Biology, 52: 165-176.

78. Ribeiro O y Uieda SV. 2005. Estrutura da comunidade de macroinvertebrados bentónicos deum 
riacho de serra em Itatinga, São Paulo, Brasil. Revista Brasileira de Zoologia, 22(3): 613-618.

79. Riss W, Ospina R y Gutiérrez JD. 2002a. Una metodología para el cálculo de valores primarios de bioindicación. Acta Biológica Colombiana, 7(2), 29-35.

80. Riss W, Ospina R y Gutiérrez JD. 2002b. Establecimiento de valores de bioindicación para los macroinvertebrados acuáticos de la Sabana de Bogotá. Caldasia, 24: 135-156.

81. RodríguezJA, Ospina R, GutiérrezJ.y Ovalle H. 2007. Densidad y biomasa de macroinvertebrados acuáticos derivantes en una quebrada tropical de montaña (Bogotá, Colombia). Caldasia, 29 (2): 397-412.

82. Rodríguez JA. 2011. Descriptores funcionales en un sistema fluvial de montaña. Santa Marta, Colombia. Tesis Ph. D. Ciencias Biología, Fac. Ciencias, Dep. Biología, U. Nacional de Colombia, Bogotá D.C.

83. Roldán G y Ramírez J. 2008. Fundamentos de limnología neotroropical. Ed. Universidad de Antioquia, Medellín, 440 p.

84. Roldán G. 1996. Guía para el estudio de los macro-invertebrados acuáticos del Departamento de Antioquía. FEN-Colombia, COLCIENCIAS-Universidad de Antioquia, Medellín, 217 p.

85. Roldán G. 2003. Bioindicación de la calidad del agua en Colombia. Uso del método BMWP/Col. Ed. Universidad de Antioquia, Medellín, 170 p.

86. Rosa BJ, Rodrigues LF, de Oliveira GS, da Gama Alves R. 2014. Chironomidae and Oligochaeta for water quality evaluation in an urban river in southeastern Brazil. Environmental Monitoring and Assessment, 186(11): 7771-7779.

87. Ruiz J, Ospina R, Gómez H y Riss W. 2000a. Guía para la identificación genérica de larvas de Quironómidos (Diptera Chironomidae) de la sabana de Bogotá. II Subfamilia Chironominae. Caldasia, 22(1): 15-33.

88. Ruiz J, Ospina R, Gómez H y Riss W. 2000b. Guía para la identificación genérica de larvas de quironómidos (Diptera: Chironomidae) de la sabana de Bogotá. III. subfamilias Tanypodinae, Podonominae y Diamesinae. Caldasia, 22 (1): 34-60.

89. Ruiz MV y Rincón ME. 2014. Calidad ecológica del río Villeta (Villeta-Cundinamarca. U. Pedagógica Nacional, Bogotá, 15 p. http://www.pedagogica. edu.co/storage/ted/articulos/ ted12_07arti.pdf, consulta noviembre de 2014.

90. Sánchez M. 2005. El índice biológico BMWP (Biological Monitoring Working Party Score), modificado y adaptado al cauce principal del río Pamplonita Norte de Santander. Bistua, 2: 54-67.

91. Segnini S. 2003. El uso de los macroinvertebrados bentónicos como indicadores de la condición ecológica de los cuerpos de agua corriente. Ecotrópicos, 16 (2): 45-63.

92. Sinclair CSy Gresens SE. 2008. Discrimination of Cricotopus species (Diptera: Chironomidae) by DNA barcoding. Bulletin of Entomological Research, 98(6): 555-563. doi: 10.1017/S0007485308005865, consulta octubre de 2014.

93. Sotelo RC, Cupul A y Rodríguez AP. 2014. Paola. Primer registro del género Clunio (Diptera: Chironomidae) asociado a las comunidades coralinas de islas Marietas, México. Revista Mexicana de Biodiversidad, 85(1): 14-23.

94. van den Honert RC y McAneney J. 2011.The 2011 Brisbane Floods: Causes, impacts and implications. Water, 3: 1149-1173.

95. Walteros JM y Paiba JE. 2010. Estudio preliminar de la comunidad de macroinvertebrados acuáticos en la Reserva Forestal Torre Cuatro. Boletín Científico Museo de Historia Natural, 14(1): 137-149.

96. Welch EB. 1992. Ecological effects of wastewater. Applied limnology and pollutant effects. Second edition. Chapman \& Hall, Massachussets, 425 p.

97. Zilli F y Gagneten A. 2005. Efectos de la contaminación por metales pesados sobre la comunidad bentónica de la cuenca del arroyo Cululú (río Salado del Norte, Argentina). INCl, 30(3): 159-165. 